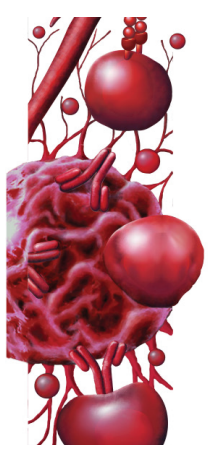

\title{
Do not forget the joint involvement of sarcoidosis
}

\begin{abstract}
A letter in response to: Crommelin $\mathrm{HA}$, Vorselaars $\mathrm{AD}$, van Moorsel $\mathrm{CH}$, Korenromp IH, Deneer VH, Grutters JC. Anti-TNF therapeutics for the treatment of sarcoidosis. Immunotherapy 6(10), 1127-1143 (2014).
\end{abstract}

Keywords: anti-TNF $\bullet$ articular $\bullet$ joint $\bullet$ sarcoidosis

We thank the authors for their excellent review on the different anti-TNF therapies used in the treatment of sarcoidosis [1]. Unfortunately, the authors did not talk about some painful events: muscular and articular involvement of sarcoidosis.

The prevalence of joint manifestations occurring during sarcoidosis is estimated at about 15 to $25 \%$ [2]. The articular manifestations of sarcoidosis may however be asymptomatic and therefore undiagnosed. These joint damages are often associated with an invasion of soft tissues (infiltration of the skin, lupus pernio) and generally occur whereas sarcoidosis has already been diagnosed. Visser et al. found that there was involvement of the large joints in 95\% of their patients, mainly in the lower limbs (96\%) and in a symmetric way $(76 \%)$ [2]. It is notably well known that bi-arthritis of the ankle should suggest the diagnosis of arthritis sarcoidosis (sensitivity 95\%, specificity 90\%) [2]. During the articular manifestations of sarcoidosis, NSAIDs should be prescribed as the first line of therapy, especially to amend arthralgia. [3]. However, NSAIDs and painkillers are not always enough, and then corticosteroids and/or synthetic diseasemodifying antirheumatic drugs (DMARDs) such as methotrexate may be considered.

Biologics, and especially anti-TNF drugs, could be prescribed during rheumatic diseases such as rheumatoid arthritis and spondyloarthritis. In cases of sarcoidosis resistant to all the previously described therapies, we have treated some of our patients with antiTNF drugs, after local multidisciplinary staff, patient information and according to the rules of the local ethics committee. What were the results of our experience anti-TNF drugs in articular manifestations of sarcoidosis [4]? There was no significant impact of the different anti-TNF drugs on articular manifestations (numbers of painful and swollen joints, DAS28 with ESR or CRP, global VAS score) of sarcoidosis, nor on the different biological indicators of inflammatory syndrome [4]. In our study, that included a small number of patients, anti-TNF halved the mean prednisone dose (6.3 vs $3.2 \mathrm{mg} /$ day) and was associated with mild adverse events: two cases of nonsevere infections and one toxidermia that resolved after treatment withdrawal. Judson et al. conducted the only trial to evaluate sarcoidosis joint manifestations under infliximab and, again, no satisfactory impact on joint disease was observed after 24 and 48 weeks of treatment [5].

Muscle involvement often goes unrecognized but is rare (1\%) and typically appears as a complication of systemic sarcoidosis [6]. The mainstay of the treatment of muscular sarcoidosis is systemic glucocorticoids therapy but corticosteroid-induced myopathy can also occur as a complication of the treatment of sarcoidosis [7]. Actually, no assessment of anti-TNF drugs in myopathy sarcoidosis is available.

\author{
Christopher Banse ${ }^{*, 1}$ \\ \& Vincent Goëb² \\ 'Rheumatology Department, Rouen \\ University Hospital, Rouen, France \\ ${ }^{2}$ Rheumatology Department, Research \\ Unit EA 4666, Amiens University \\ Hospital, University of Picardie \\ Jules-Verne, Amiens, France \\ *Author for correspondence: \\ Tel.: + +330232888990 \\ Fax: +330232880439 \\ christopher.banse@chu-rouen.fr
}

Future $\because$ Medicine part of 
The risk of developing or aggravating pulmonary fibrosis is higher when extrapulmonary involvement is uncontrolled so every manifestation of sarcoidosis should be searched at the early beginning and during the follow-up of the disease [8]. To date, anti-TNF efficacy has not been proven in treating joint sarcoidosis and should be considered cautiously and only when the joint disease is chronic, disabling and resistant to NSAIDs and methotrexate.

\section{Disclaimer}

The opinions expressed in this article are those of the authors and do not necessarily reflect the views of Future Medicine Ltd.

\section{Financial \& competing interests disclosure}

The authors have no relevant affiliations or financial involvement with any organization or entity with a financial interest in or financial conflict with the subject matter or materials discussed in the manuscript. This includes employment, consultancies, honoraria, stock ownership or options, expert testimony, grants or patents received or pending, or royalties.

No writing assistance was utilized in the production of this manuscript.

\section{References}

1 Crommelin HA, Vorselaars AD, van Moorsel CH, Korenromp IH, Deneer VH, Grutters JC. AntiTNF therapeutics for the treatment of sarcoidosis. Immunotherapy 6(10), 1127-1143 (2014).

2 Visser H, Vos K, Zanelli E et al. Sarcoid arthritis: clinical characteristics, diagnostic aspects, and risk factors. Ann. Rheum. Dis. 61, 499-504 (2002).

3 Baughman RP, Costabel U, Du Bois RM. Treatment of sarcoidosis. Clin. Chest Med. 29, 533-548 (2008).

4 Banse C, Bisson-Vaivre A, Kozyreff-Meurice M, Vittecoq $\mathrm{O}$, Goëb V. No impact of tumor necrosis-factor antagonists on the joint manifestations of sarcoidosis. Int. J. Gen. Med. 22(6), 605-611 (2013).

5 Judson MA, Baughman RP, Costabel U et al. Efficacy of infliximab in extrapulmonary sarcoidosis: results from a randomised trial. Eur. Respir. J. 31, 1189-1196 (2008).

6 Fayad F, Duet M, Orcel P, Lioté F. Systemic sarcoidosis: the "leopard-man" sign. Joint Bone Spine. 73(1), 109-112 (2006).

7 Khaleeli AA, Edwards RH, Gohil K et al. Corticosteroid myopathy: a clinical and pathological study. Clin. Endocrinol. (Oxf). 18(2), 155-166 (1983).

8 Gran JT, Bøhmer E. Acute sarcoid arthritis: a favourable outcome? A retrospective survey of 49 patients with review of the literature. Scand. J. Rheumatol. 25, 70-73 (1996). 